\title{
Influence of Transformational Leadership on Novelty of Product Ideas: Validation of Theoretical Model
}

\author{
Jasminka Ahmetasevic (PhD Candidate) \\ Visoka Poslovno Tehnička Škola, Doboj, Bosnia and Herzegovina \\ Merdzana Obralic (Assistant Professor Doctor) \\ International Burch University, Ilidža, Bosnia and Herzegovina
}

Doi: 10.19044/esj.2018.v14n7p156 URL:http://dx.doi.org/10.19044/esj.2018.v14n7p156

\begin{abstract}
This study investigates the relationship between transformational leadership and novelty of product ideas. Conceptual approach based on the theory has been applied to provide better understanding of the relationship between transformational leadership and two knowledge creation modes (internalization, externalization). Mediating roles of internalization and externalization in a relationship between transformational leadership and novelty of product ideas will be investigated. After conducting a systematic literature review, theoretical model will be proposed and validated using regression analysis. Main software packages used in this study are Microsoft Word and Statistical Package for Social Sciences. This is one of the first studies to explore the link between transformational leadership and novelty of product ideas. It, however, has two important knowledge creation modes, internalization and externalization as mediators. The main finding of this paper is the validation of theoretical model which mostly confirmed assumptions based on previous literature. Regression tests indicated confirmation of five hypotheses, while mediation tests indicated partial mediation of Internalization and Externalization. It is recommended that future research should conduct validation of the model using other methodologies and different samples, or same samples in different time periods, to provide stronger empirical evidence for the confirmation of tested hypotheses.
\end{abstract}

Keywords: Transformational Leadership, Internalization, Externalization, Novelty of Product Ideas, Regression

\section{Introduction}

In a world where innovation plays a key role in the sustainability of many companies across the globe, it is never enough for empirical evidence to support both researchers and practitioners. This study focuses on something 
not so well adressed by previous studies. Therefore, this focus is on the mediators of relationship between transformational leadership and novelty of product ideas which gives it a superior theoretical and practical significance.

Consequently, leaders are investing significant efforts to find out new ways of improving novelty of product ideas, and offering to market something new that can generate new profits. Being knowledgeable about potential mediators of the relationship between the leader's approach and novelty of product ideas may be crucial for the accomplishment of this goal. Therefore, the findings of this study are very important for practitioners to improve their businesses.

Literature review analysis trigered two main research questions:

- $\quad$ Are there any effects of Transformational Leadership on Novelty of Product Ideas?

- What is the type of effects between Transformational Leadership and Novelty of Product Ideas, are they direct or indirect?

- $\quad$ Are externalization and internalization playing any mediating role within the relationship between Transformational Leadership and Novelty of Product Ideas, are they direct or indirect?

However, the primary objective of this study is to investigate direct effects of transformational leadership on novelty of product ideas, and also indirect effects via mediators. The objectives of this study can be summarized as follows:

- To investigate direct effects of transformational leadership on novelty of product ideas;

- To investigate direct effects of transformational leadership on externalization and internalization, as well as to investigate direct effects of externalization and internalization on novelty of product ideas;

- To investigate mediating roles of externalization and internalization in a relationship between transformational leadership on novelty of product ideas.

The main statistical methods applied to achieve the above mentioned goals are descriptive statistics and regression analysis using Microsoft Excel and the Statistical Package for Social Sciences (SPSS).

Thus, the results of this study will help researchers understand the nature of effects of transformational leadership on novelty of product ideas in terms of classifying them as direct or indirect. Also, it will test two potential mediators in the mentioned relationship. Through this way, contribution to theory will be achieved. Furthermore, the results of this study will help leaders all across the globe to better understand the role of externalization and internalization based on the process of using transformational leadership tactics to generate higher level of novelty of product ideas. 
Therefore, the following section will define the key variables and relationships in the study, and it would also propose the theoretical framework. Methodology section will provide more details about the statistical methods applied in the study. The result section will explain and briefly discuss all the findings. The final section will conclude and summarize the most important aspects of the study.

\section{Literature Review}

In the literature review, we focus on transformational leadership and two knowledge creation modes of novelty of product ideas.

\section{Transformational Leadership}

Zwingmann, Wegge, Wolf, Rudolf, Schmidt and Richter (2014) reported that transformational leaders inspire followers with an interesting vision, high standards, and make them optimistic about their future goal attainment. Transformational leadership helps to encourage creativity and the follower's intellectual work. Zwingmann et al. (2014) found a significant relationship between followers and transformational leadership.

Nemaei (2012) revealed transformational leadership as individuals who increase confidence, awareness, interest, and motivation in the followers by moving the follower's interest from their personal existence to the existence of the organizational group. Chen and Chang (2013) argued that transformational leadership can relieve the introduction of new ideas by the motivation and stimulation of follower. Transformational leadership motivate followers to achieve more and more compared to what the follower planned to achieve. By motivating and encouraging employees to think creatively, transformational leadership can magnify innovation. Through that way, they can create teams of innovative people, promote mutual trust, and create vision among followers (Givens, 2008; Chen \& Chang, 2013).

If everyone in an organization is creative, it would help the organization to become creative (Jaiswal \& Dhar, 2015). Generation of new ideas could be implemented by one or more employees. Transformational leadership promotes group creativity (generation of new ideas implemented by more employees) (Hypia \& Parjanen, 2013). When group creativity occurs, it is called group brainstorming technique for generation of novel ideas (Phipps, Prieto \& Verma, 2012). If organization creates and share knowledge among groups, it is more useful and effective for transformational leadership (Bryant, 2003). By sharing knowledge between them, transformational leadership encourage communication between team members (Zagoršek, Dimovski \& Škerlavaj, 2009). Through that way, they encourage the expression of different views and ideas (Hoch, 2013). 


\section{Transformational Leadership and Knowledge Creation}

Subsequently, there are many reserchers who elaborated on the relationship between transformational leadership and knowledge creation (Mitchell \& Boyle, 2009; Tse \& Mitchell, 2010; Bryant, 2003; Hayat, Hasanvand, Nikkakhlag \& Dehghani, 2015; Singh, 2008; Zagoršek, Dimovski $\&$ Škerlavaj, 2009). They found that transformational leadership has a positive significant effect on knowledge creation. Transformational leaders encourage open, honest, and timely communication with organizational members (Zagoršek, Dimovski \& Škerlavaj, 2009). They investigated that organizational members collect information from source outside the company. Therefore, the following hypotheses were presented:

H1: Transformational leadership has significant impact on Internalization. H2: Transformational leadership has significant impact on externalization. Transformatinal Leadership and Novelty of Product Ideas with Knowledge Modes

Transfromational leaders can be defined as leaders who positively envision the future scenarios for the organizations, engage primarily in improving employee's self-confidence by helping them to realize their potential, communicate an achievable mission and vision of the organizations to employees, and participate with employees to identify their needs and working out collaboratively to satisfy their needs (Peterson, Walumbwa, Byron \& Myrowitz, 2009). Biransnar, Albufalasa and Bader (2013) indicated a significant relationship between transformational leadership and knowledge management process on predicting product and process innovation. They showed results that knowledge transfer and application partially mediated the relationship between transformational leadership and product innovation. Considering the concepts above, the following hypotheses were proposed:

H3: Internalization mediates relationship between transformational leadership and novelty of product ideas.

H4: Externalization mediates relationship between transformational leadership and novelty of product ideas.

\section{Transformational Leadership and Novelty of Product Ideas}

Previous work has revealed the influence of transformational leaderhip and innovation (Afsar, Badir \& Saeed, 2014; Jaiswal \& Dhar, 2015; Mokhber, Ismail \& Vakilbashi, 2015; Hyypia \& Parjanen, 2013; De Jong \& Den Hartog, 2007; Bryant, 2003). Thus, based on their studies, the hypothesis of this study is as follows:

H5:Transformational leadership has significant impact on novelty of product ideas. 


\section{Internalization and Novelty of Product Ideas}

Subsequently, there are many authors who investigated the link between internalization and novelty of product ideas (Lee \& Choi, 2003; Schulze \& Hoegl, 2008). They found positive relationship between internalization and novelty of product ideas. The study proposed the following hypothesis:

H6: Internalization has significant impact on the novelty of product ideas Externalization and Novelty of Product Ideas

There are many authors who investigated relationship between externalization and novelty of product ideas (Lee \& Choi, 2003; Schuzle \& Hoegl, 2008; Kanapathy, Khong \& Dekkers, 2014). Lee and Choi found positive relationship while Schuzle and Hoegl found a negative relationship between externalization and novelty of product ideas. Kanapathy, Khong and Dekkers (2014) found a positive relationship between external source of ideas (supplier) and new product development. Hence, this study infers the following assumption:

H7: Externalization has significant impact on the novelty of product ideas Furthermore, the proposed theoretical model is presented in Figure 1 below:

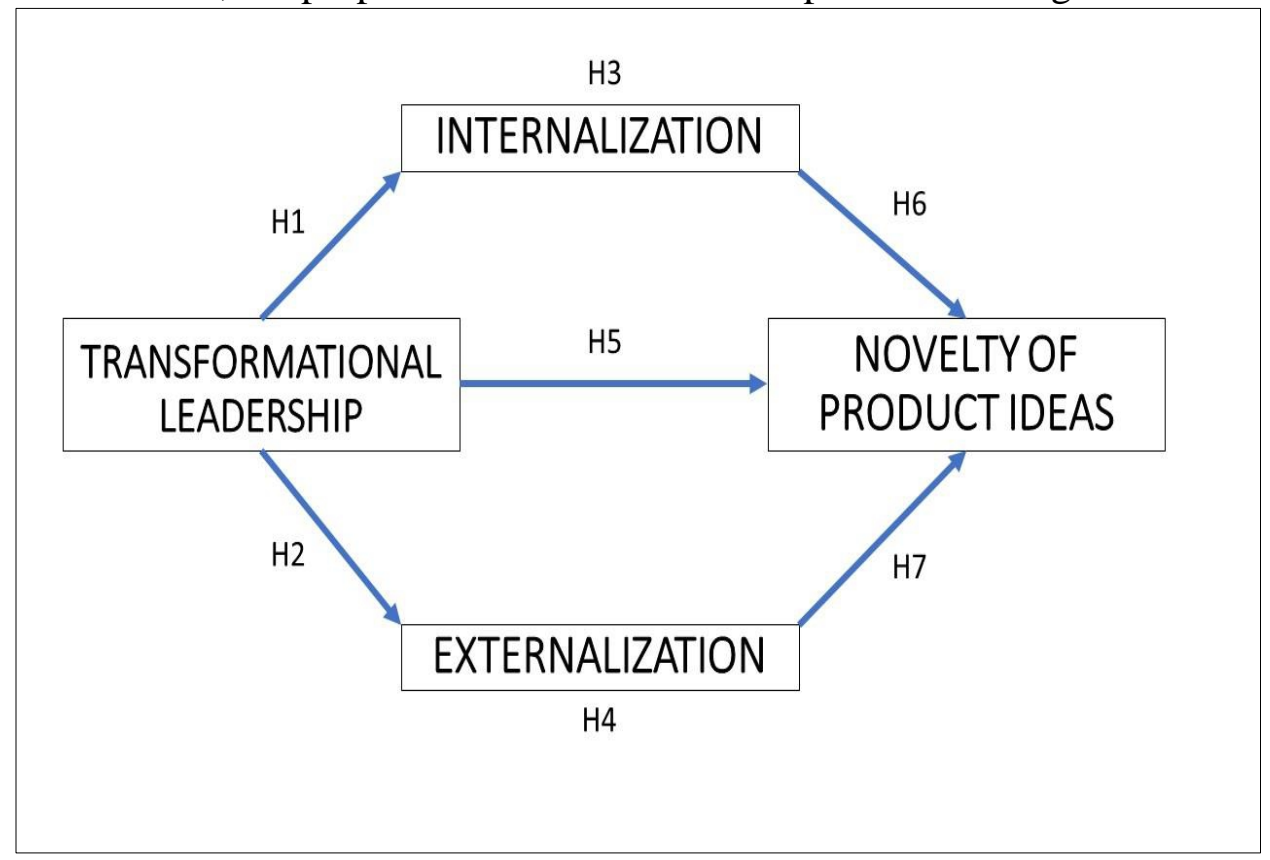

Figure 1. Proposed theoretical model

\section{Methodology}

Measurement Instrument

The data used in this study were collected by means of a structured survey. The survey was prepared using the scales previously used by 
researchers and already proven as both reliable and valid in measuring Transformational Leadership, Externalization, Internalization, and Novelty of Product Ideas.

Very useful scales of Externalization (4 items scale), Internalization (4 items scale), and Novelty of Product Ideas (3 items scale) were provided by Schuzle and Hoegl (2008), while very useful scales for Transformational Leadership (6 items scale) were provided by Hoch, Pearce and Welzel (2010).

\section{Sample}

The main target population of this study are companies with more than 250 employees headquartered in Federation of Bosnia and Herzegovina. After sending the survey, 46 companies answered with complete response.

\section{Statistical Methods used for the Analysis}

To statistically process received responses, Microsoft Excel and SPSS Statistics 18 software package were utilized. While Microsoft Excel was used for descriptive statistics, SPSS 18 was used for Exploratory Factor Analysis, Reliability tests, and Regression analysis.

\section{Results}

\section{Demographics}

In total, 46 companies participated in this study. There is slightly more males than females among respondents. Most of the respondents are bachelors of science, followed by masters, high school graduates and, finally, only $2.17 \%$ were able to complete their doctorate level. When it comes to working experience, $28.26 \%$ of respondents are having from 0 to 5 years of experience, and same portion of sample has 6 to 10 years of experience. Thus, the smallest percentage $(4.35 \%)$ are highly experienced respondents with over 30 years working experience. Detailed review of all important characteristics of the sample used in this study is available in Table 1.

\begin{tabular}{|c|c|c|c|}
\multicolumn{4}{c}{ Table 1. Sample Characteristics } \\
\hline Variable & Alternative & Number & Percentage \\
\hline \multirow{3}{*}{ Gender } & Male & 26 & 56,52 \\
\cline { 2 - 4 } & Female & 20 & 43,48 \\
\hline \multirow{3}{*}{ Education Level } & High School & 3 & 6,52 \\
\cline { 2 - 4 } & Undergraduate & 32 & 69,57 \\
\cline { 2 - 4 } & Master & 10 & 21,74 \\
\cline { 2 - 4 } & Doctorate & 1 & 2,17 \\
\hline \multirow{5}{*}{ Job Experience } & 0-5 years & 13 & 28,26 \\
\cline { 2 - 4 } & 6-10 years & 13 & 28,26 \\
\cline { 2 - 4 } & $11-20$ years & 12 & 26,09 \\
\cline { 2 - 4 } & 21-30 years & 6 & 13,04 \\
\cline { 2 - 4 } & over 30 years & 2 & 4,35 \\
\hline
\end{tabular}




\section{Exploratory Factor Analysis and Reliability}

With the aim to reduce unnecessary items from the survey where necessary, exploratory factor analysis (EFA) has been conducted for each variable individually. Principal component analysis using Varimax rotation approach has been conducted using SPSS Statistics 18 software package. Furthermore, reliability of each scale has been assessed using cronbach's alpha values.

\section{Transformational Leadership - EFA and Reliability Assessment}

Table 1 indicates that all items' loadings of Transformational Leadership (TL) variable are higher than 0.7, which means that the scale measures what it is supposed to measure. Therefore, there was no need to eliminate any item from the measurement instrument. Moreover, Cronbach's Alpha value of 0.957 indicated strong reliability level, as it significantly exceeds the minimum acceptable value of 0.7 as defined by Cronbach and Richard (2004). Mean values and standard deviation values indicated no unusual discrepancy based on the answers of respondents.

Table 1. Loadings, Coefficient Alpha, Mean and St. Dev. for Transformational Leadership

\begin{tabular}{|c|c|c|c|}
\hline $\begin{array}{c}\text { Transformational Leadership } \\
\text { (Cronbach's Alpha 0.957) }\end{array}$ & Loadings & Mean & St. Dev. \\
\hline $\begin{array}{c}\text { My team leader provides a clear vision of whom and } \\
\text { what our team is. }\end{array}$ & 0.839 & 4.26 & 0.74 \\
\hline $\begin{array}{c}\text { My team leader is driven by higher purposes or } \\
\text { ideals. }\end{array}$ & 0.780 & 4.13 & 0.93 \\
\hline My team leader shows enthusiasm for my efforts. & 0.890 & 4.22 & 0.79 \\
\hline $\begin{array}{c}\text { My team leader encourages me to rethink ideas } \\
\text { which has never been questioned before. }\end{array}$ & 0.849 & 3.87 & 0.96 \\
\hline $\begin{array}{c}\text { My team leader seeks a broad range of perspectives } \\
\text { when solving problems. }\end{array}$ & 0.841 & 4.17 & 0.85 \\
\hline $\begin{array}{c}\text { My team leader encourages me to go above and } \\
\text { beyond what is expected. }\end{array}$ & 0.744 & 4.17 & 0.77 \\
\hline
\end{tabular}

\section{Internalization - EFA and Reliability Assessment}

Table 2 indicates that all items' loadings of Internalization (I) variable are higher than 0.6, which means that the scale measures what it is supposed to measure. Therefore, there was no need to eliminate any item from the measurement instrument. Moreover, Cronbach's Alpha value of 0.823 indicated strong reliability level, as it significantly exceeds the minimum acceptable value of 0.7 as defined by Cronbach and Richard (2004). Mean values and standard deviation values indicated no unusual discrepancy based on the answers of respondents. 
Table 2. Loadings, Coefficient Alpha, Mean and Standard Deviation for Internalization

\begin{tabular}{|c|c|c|c|}
\hline Internalization (Cronbach's Alpha 0.823) & Loadings & Mean & St. Dev. \\
\hline $\begin{array}{c}\text { We spent a lot of time in trial-and-error } \\
\text { (experimenting),thereby developing a sense for the } \\
\text { feasibility of our thoughts regarding the functionality } \\
\text { of the technology. }\end{array}$ & 0.910 & 3.89 & 0.97 \\
\hline $\begin{array}{c}\text { We spent a lot of time in trial-and-error } \\
\text { (experimenting), thereby developing a sense for the } \\
\text { feasibility of our thoughts regarding customer needs. }\end{array}$ & 0.898 & 3.93 & 0.93 \\
\hline $\begin{array}{c}\text { We spent a lot of time in trial-and-error } \\
\text { (experimenting), thereby developing a sense for the } \\
\text { feasibility of our thoughts regarding the procedure of } \\
\text { creating novel product ideas. }\end{array}$ & 0.770 & 3.87 & 0.98 \\
\hline $\begin{array}{c}\text { We spent a lot of time systematically testing our } \\
\text { theoretical knowledge about customer needs. }\end{array}$ & 0.665 & 3.57 & 1.07 \\
\hline
\end{tabular}

\section{Externalization - EFA and Reliability Assessment}

Table 3 indicates that all items' loadings of Externalization (E) variable are higher than 0.7 which means that the scale measures what it is supposed to measure. Therefore, there was no need to eliminate any item from the measurement instrument. Moreover, Cronbach's Alpha value of 0.857 indicated strong reliability level, as it significantly exceeds the minimum acceptable value of 0.7 as defined by Cronbach and Richard (2004). Mean values and standard deviation values indicated no unusual discrepancy based on the answers of respondents.

Table 3. Loadings, Coefficient Alpha, Mean and St. Dev. for Externalization

\begin{tabular}{|c|c|c|c|}
\hline Externalization (Cronbach's Alpha 0.857) & Loadings & Mean & St. Dev. \\
\hline $\begin{array}{c}\text { We spent a lot of time reflecting collectively and } \\
\text { framing our ideas or solutions with regard to customer } \\
\text { needs. }\end{array}$ & 0.859 & 4.37 & 0.74 \\
\hline $\begin{array}{c}\text { We spent a lot of time interviewing competent people } \\
\text { about ideas or solutions with regard to relevant } \\
\text { technologies. }\end{array}$ & 0.863 & 4.11 & 0.90 \\
\hline $\begin{array}{c}\text { We spent a lot of time interviewing competent people } \\
\text { about ideas or solutions with regard to customer needs. }\end{array}$ & 0.903 & 4.11 & 0.92 \\
\hline $\begin{array}{c}\text { We spent a lot of time creating detailed descriptions } \\
\text { (e.g., protocols, presentations, reports) containing } \\
\text { newly developed knowledge about customer needs }\end{array}$ & 0.753 & 3.91 & 1.05 \\
\hline
\end{tabular}

\section{Novelty of Product Ideas - EFA and Reliability Assessment}

Table 4 indicates that all items' loadings of Novelty of Product Ideas (NPI) variable are higher than 0.7 , which means that the scale measures what it is supposed to measure. Therefore, there was no need to eliminate any item from the measurement instrument. Moreover, Cronbach's Alpha value of 0.837 indicated strong reliability level, as it significantly exceeds the minimum acceptable value of 0.7 as defined by Cronbach and Richard (2004). Mean 
values and standard deviation values indicated no unusual discrepancy based on the answers of respondents.

Table 4. Loadings, Coefficient Alpha, Mean and St. Dev. for Novelty of Product Ideas

\begin{tabular}{|c|c|c|c|}
\hline Novelty of Product Ideas (Cronbach's Alpha 0.837) & Loadings & Mean & St. Dev. \\
\hline $\begin{array}{c}\text { Many of the ideas generated were new to the } \\
\text { company. }\end{array}$ & 0.773 & 3.89 & 0.82 \\
\hline $\begin{array}{c}\text { Many of ideas generated were new to our existing } \\
\text { customers. }\end{array}$ & 0.938 & 3.91 & 0.84 \\
\hline Many of ideas generated were new to the market. & 0.892 & 3.65 & 0.92 \\
\hline
\end{tabular}

\section{Regression Analysis}

After conducting regression analysis in SPSS Statistics 18 software package, findings were reported in Table 5 and Table 6. Table 5 indicated confirmation of hypotheses $1,2,6,7$, and 5 . At confidence interval of $95 \%$, all $\mathrm{p}$ values were smaller than 0.05 , indicating significant influencing relationships between tested hypotheses.

Table 5. Regression Results

\begin{tabular}{|c|c|c|c|c|}
\hline \multicolumn{3}{|c|}{ Hypotheses } & p (sig. Alpha) & $\mathrm{t}$ value \\
\hline $\mathrm{H} 1$ & $\rightarrow$ & $\mathrm{I}$ & $0.019 *$ & 2.427 \\
\hline $\mathrm{H} 2$ & $\rightarrow \quad \mathrm{TL}$ & $\mathrm{E}$ & $0.01 *$ & 3.641 \\
\hline H6 & $\longrightarrow \mathrm{I}$ & NPI & $0.012 *$ & 2.616 \\
\hline $\mathrm{H} 7$ & $\rightarrow E$ & NPI & $0.000 * * *$ & 4.188 \\
\hline $\mathrm{H} 5$ & $\longrightarrow \mathrm{TL}$ & NPI & $0.001 * *$ & 3.444 \\
\hline \multicolumn{5}{|c|}{$* \mathrm{P}<0.05 ; * * \mathrm{P}<0.01 ; * * * \mathrm{P}<0.001$} \\
\hline \multicolumn{5}{|c|}{$\begin{array}{c}\text { TL - Transformational Leadership; I - Internalization; E - Externalization; NPI - Novelty } \\
\text { of Product Ideas }\end{array}$} \\
\hline
\end{tabular}

Table 6 shows that considering mediation rules of Baron and David (1986), both mediation tests were conducted and was revealed to be significant at all three paths (path $a, b$ and c). This means that partial mediation of Internalization and Externalization exists, and as a consequence, hypotheses 3 and 4 were partially confirmed.

Table 6. Mediation Tests

\begin{tabular}{|c|c|c|c|c|c|}
\hline \multicolumn{2}{|c|}{ Hypotheses } & Path a & Path $\mathrm{b}$ & Path c & Status \\
\hline H3 & TL $\rightarrow$ I $\rightarrow$ NPI & $\begin{array}{c}\text { TL-I } \\
p=0.019\end{array}$ & $\begin{array}{c}\text { I-NPI } \\
p=0.012\end{array}$ & $\begin{array}{c}\text { TL-NPI } \\
p=.001\end{array}$ & $\begin{array}{c}\text { Partial } \\
\text { Mediation }\end{array}$ \\
\hline H4 & TL $\rightarrow$ E $\rightarrow$ NPI & $\begin{array}{c}\text { TL-E } \\
p=0.010\end{array}$ & $\begin{array}{c}\text { E-NPI } \\
p=0.000\end{array}$ & $\begin{array}{c}\text { TL-NPI } \\
p=.001\end{array}$ & $\begin{array}{c}\text { Partial } \\
\text { Mediation }\end{array}$ \\
\hline
\end{tabular}

Path a are direct effects of independent variable on mediator. Path $b$ are direct effects of mediator on dependent variable. Path $\mathrm{c}$ are direct effects of independent on dependent variable (Baron \& David, 1986).

From Table 7, we see that all hypotheses are confirmed. While hypotheses 1,2, 6 and 7 are completely confirmed, hypotheses 3 and 4 are partially confirmed. 
Table 7. Summary of hypotheses

\begin{tabular}{|c|c|c|}
\hline$\#$ & Hypotheses & Status \\
\hline H1 & Transformational leadership has significant impact on Internalization. & Confirmed \\
\hline H2 & Transformational leadership has significant impact on externalization. & Confirmed \\
\hline H3 & $\begin{array}{c}\text { Internalization mediates relationship between transformational } \\
\text { leadership and novelty of product ideas. }\end{array}$ & Partially confirmed \\
\hline H4 & $\begin{array}{c}\text { Externalization mediates relationship between transformational } \\
\text { leadership and novelty of product ideas. }\end{array}$ & Partially confirmed \\
\hline H5 & $\begin{array}{c}\text { Transformational leadership has significant impact on novelty of } \\
\text { product ideas. }\end{array}$ & Confirmed \\
\hline H6 & Internalization has significant impact on the novelty of product ideas. & Confirmed \\
\hline H7 & Externalization has significant impact on the novelty of product ideas. & Confirmed \\
\hline
\end{tabular}

\section{Conclusion}

In order to explain the relationship between Transformational Leadership (TL), Internalization (I), Externalization (E) and Novelty of Product Ideas (NPI), based on literature review, seven hypotheses were proposed and tested. The questionnaire prepared on the basis of literature review has been used as an instrument. The managers of 46 large companies in $\mathrm{FBiH}$ responded to the survey. Regression results indicated a significant and positive effects of TL on I and E. Also, results revealed a significant and positive effects of I and E on NPI, as well as the one of TL on NPI. According to findings, Internalization and Externalization partially mediate relationship between TL and NPI. Considering relatively small sample size as the main limitation of this study, it is highly recommended for future research to provide empirical evidence using larger sample. Through that way, they would be able to offer stronger validation of proposed theoretical framework.

\section{References:}

1. Afsar, B., Badir, F., \& Saeed, BB. (2014). Transfromational leadership and innovative work behavior. Emerald Group Publishing limited, 114 (8), 1270-1300.

2. Baron, R. M. \& David, AK. (1986). Moderator Mediator Variables Distinction in Social Psychological Research: Conceptual, Strategic, and Statistical Considerations. Journal of Personality and Social Psychology, 51(6), 1173-82.

3. Birasnav, M., Alnbufalasa, M., \& Bader, Y. (2013). The roles of transfromational leadership and knowledge management processes on predicting product and process innovation: An empirical study developed in Kingdom of Bahrain, 11 (12), 64-75.

4. Bryant, S. E. (2003). The role of transformational and transactional leadership in creating, sharing and exploiting organizational knowledge. Journal of leadership and organizational studies, 9 (4), $32-44$. 
5. Chen, Y.S. \& Chang, C.-H. (2013). The determinants of green product development performance: green dynamic capabilitis, green transformational leadership, and green creativity. Journal of Business Ethics, 116 (1), 107-119.

6. Cronbach, L. J. \& Richard, J. S. (2004). My Current Thoughts on Coefficient Alpha and Successor Procedures. Educational and Psychological Measurement, 64(3), 391-418.

7. De Jong, J. P. J. \& Den Hartog, D. N. (2007). How leaders influence employees' innovative behaviour. European Journal of innovation, 10 (1), 41-64.

8. Givens, R. J. (2008). Transformational leadership: the impact on organiizational and personal outcomes. Emerging leadership journeys 1, 4-24. ISSN 1941-4684.

9. Hayat, A., Hasanvand, M.M., Nikakhlag, S., \& Dehghani, M.R. (2015). The role of transformational leadership and its knowledge management processes. Journal of Health Management \& Informatics, 2 (2), 41-46.

10. Hoch, J. E., Pearce, C. L., \& Welzel, L. (2010). Is the Most Effective Team Leadership Shared?: The Impact of Shared Leadership, Age Diversity and Coordination on Team Performance. Journal of Personnel Psychology, Vol. 9 (3), 105-116

11. Hoch, J.E. (2013). Shared Leadership and Innovation: The role of vertical leadership and employee integrity. Journal of Business and Psychology, 28 (2), 159-174. Springer.

12. Hyypia, M., \& Parjanen, S. (2013). Boosting creativity with transformational leadership in fuzzy front-end innovation process. Interdisciplinary Journal of Informaitons, Knowledge, and Management, 8, 21-41.

13. Jaiswal, N. K., \& Dhar, R. L. (2015). Transformational leadership, innovation climate, creative self -efficacy and employee creativity: A multilevel study. International Journal od Hospitality Management, 51, 30-41.

14. Kanapathy, K., Khong, K. W., \& Dekkers, R. (2014). New product development in an emerging economy: Analysing the role of supplier involvmnet practices by using bayesian markov chain monte carlo technique. Jorunal of Applied Mathematics 2014, Article ID 542303, $1-12$.

15. Lee, H. \& Choi, B. (2003). Knowledge management enablers, processes, and organizational performance: and integrative view and empirical examination. Journal of Management Information Systems, 20 (1), 179-228. 
16. Mitchell, R. J. \& Boyle, B. (2009). A theoretical model of transformational leadership's role in diverse teams. Leadership \& Organization Development Journal, 30 (5), 455-474.

17. Mokhber, M., Ismail, W. K. bin W., \& Vakilbashi, A. (2015). Effect of trnasformational leadership and its components on organizational innovation. Journal of Management Studies, 8 (2), 221-241.

18. Nemaei, B. (2012). The imapct of participative leadership on employee's motivation, job satisfaction and innovation. Dissertation. British Univesrity. Dubai, 1-31.

19. Peterson, S. J., Walumbwa, F.O., Byron, K., \& Myrowitz, J. (2009). CEO positive pscyhological traits, transformational leadership, and firm performance in high-technology start-up and established firm. Journal of Management, Vol. 35, 348-368.

20. Phipps, S. T. A., Prieto, L. C., \& Verma, S. (2012). Holding the helm: exploring the influence of transformational leadership on group creativity, and the moderating role of organiizational learning culture. Journal of Organizational Culture, Communication and Conflicts, 16 (2), 145-156.

21. Schuzle, A., \& Hoegl, M. (2008). Organizational knowledge creation and the generation of new product ideas: A behavioral approach, 37, $1742-1750$.

22. Singh, K. (2008). Relationship between learning organization and transformational leaderhsip: banking organization in India. Relationship between learning organization and transformational leadership. Journal of Business and Management Science. 97-111. ISSN 1985-692X.

23. Tse, H. M., \& Mitchell, R. (2010). A theoretical model of transformational leadership and knowledge creation. The role of openmindedness norms and leader-member exchange. Journal of Management \& Organization, 16 (1), 83-99.

24. Zagoršek, H., Dimovski, V., \& Škerlavaj (2009). Transactional and transformational leadership impacts on organizational learning. Jorunal of Eat European Management Studies, 14 (2), 144-165.

25. Zwingmann, I., Wegge, J., Wolf, S., Rudolf, M., Schmidt, M., \& Richter, P. (2014). Is trnasformational leadership helathy for employees? A multilevel analysis in 16 nations. Journal of research in human. Health promotion through leadership, 24-51. 